\title{
P091: Timely administering prophylactic antibiotics
}

Y Yau ${ }^{1 *}, I C N T^{1}, I_{\text {Wong }}^{2}$

From 2nd International Conference on Prevention and Infection Control (ICPIC 2013)

Geneva, Switzerland. 25-28 June 2013

\section{Introduction}

It is well documented that prophylactic antibiotic could reduce surgical site infection significantly providing that it is given timely with right drug and right dose. However, administering prophylactic antibiotic in a timely manner is not easy. Several factors such as low awareness of importance of timing on prophylactic antibiotic given, the workflow, ease of administration and perception of individual responsibility toward the administration could all contribute to the failure of given timely antibiotic to reduce surgical infection.

\section{Objectives}

To investigate how these problems were tackled in an elective surgical hospital in order to achieve timely administering surgical prophylactic antibiotic.

\section{Methods}

During the period 2009 to 2012, all anesthetic records of orthopedic operation performed at the Duchess of Kent Children's Hospital at Sandy Bay were reviewed. Data on time, administrator of prophylactic antibiotic, logistic of antibiotics being issued, methods of safety guide for administration and infection control rate were collected.

\section{Results}

- Total 6061 cases were reviewed.

- $99.9 \%$ of the prophylactic antibiotics were given within 15-45 minutes interval before operation.

- $100 \%$ cases went through the safety check list by nurse.

- Anesthesiologist administered all the antibiotics while surgeon prescribed all prophylactic antibiotics.

- All prophylactic antibiotics were given in operating theater except Vancomycin.

- However, 99\% antibiotics went through their regular route to OT.
- Infection rate was $0.13 \%$ over these 4 years.

\section{Conclusion}

Clearly defined roles and responsibility in the process of prophylactic antibiotic administration were essential. Safety check list helped to enforce the guidelines. Monitoring the outcome alerted stakeholders to take necessary action. Successful transfer evidence-based guidelines into daily practice required multiple interventions and support from top management to frontline staff were vital.

\section{Disclosure of interest}

None declared.

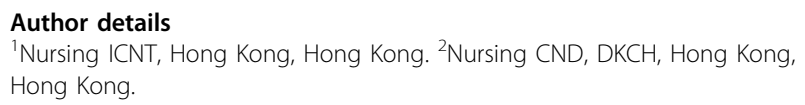

Published: 20 June 2013

doi:10.1186/2047-2994-2-S1-P91

Cite this article as: Yau et al:: P091: Timely administering prophylactic antibiotics. Antimicrobial Resistance and Infection Control 2013 2(Suppl 1):P91.

${ }^{1}$ Nursing ICNT, Hong Kong, Hong Kong

Full list of author information is available at the end of the article

(c) 2013 Yau et al; licensee BioMed Central Ltd. This is an Open Access article distributed under the terms of the Creative Commons 